\title{
O cravo e as baleias: a trajetória de Francisco Peres de Sousa, professor de música e homem de negócios (c. 1740-1782)
}

\author{
The Harpsichord and the Whales: The Trajectory of Francisco \\ Peres de Sousa, Music Teacher and Businessman (ca. 1740-1782)
}

Romulo Valle Salvino*

\section{Resumo}

Durante o Antigo Regime português, os contratos de tributos e direitos régios foram importante instrumento de governação, além de meio de enriquecimento e ascensão social para os homens de negócios. O ingresso no pequeno círculo dos principais contratadores exigia não só a possibilidade de arregimentar capital financeiro, mas também um sólido capital social dos dois lados do Atlântico. Este trabalho, com base em diversas fontes primárias, estuda o caso de Francisco Peres de Sousa, professor de música na casa do marquês de Pombal, que logrou estabelecer-se como homem de negócios e participar de importantes arrematações na segunda metade do século XVIII. Ele foi tanto líder oficial de certos empreendimentos quanto sócio da companhia de Inácio Pedro Quintela, que dominou a pesca da baleia e o estanco do sal no Brasil durante décadas. Sua permanência nesse mercado, ainda que como testa-de-ferro, prova a importân-

\section{Abstract}

During the Portuguese Old Regime, contracts of royal rights and tributes were an important instrument of government and a means of enrichment and social ascension for businessmen. The entry into the small circle of major contractors demanded not only the possibility of financial capital but also a solid social capital on both sides of the Atlantic. This work, based on several primary sources, examines the Francisco Peres de Sousa's case, a music teacher at the Marquis of Pombal's house, who managed to establish himself as a businessman and to participate in important gatherings from the second half of the eighteenth century. Peres de Sousa was both an official leader of certain enterprises and a partner of the company of Inácio Pedro Quintela, which dominated the whale fishing and the salt monopoly in Brazil for decades. Peres de Sousa stayed afloat in this market, albeit as a stooge

*Universidade de Brasília (UnB), Brasília, DF, Brasil. romulovs@uol.com.br <http://orcid.org/00000001-7290-8032> 
cia das redes de relacionamento e da proteção régia para a atividade dos principais contratadores.

Palavras-chave: América portuguesa; pesca de baleias; contratos do sal; período pombalino. to other characters, proves the importance of network relations and royal protection for contractors.

Keywords: Portuguese America; whale fishing; salt contracts; Pombaline period.

\section{UMA CARREIRA ENTRE OS SALÕES DE LISBOA E O BRASIL}

Durante quatro décadas, entre os anos 1740 e 1780, o homem de negócios lisboeta Francisco Peres de Sousa esteve ligado a diversos empreendimentos no Brasil, desde uma tentativa malograda de estabelecer navios-correio entre o Reino e os principais portos brasileiros, até o arrendamento de contratos régios em diversas praças. Em algumas vezes foi, pelo menos oficialmente, o investidor principal. Em outras, surgiu como parte de sociedades, a principal delas com os Quintelas, personagens bastante conhecidos na história das companhias de comércio e dos principais monopólios portugueses na segunda metade do século XVIII. Nesse período, que vai da última década do reinado de João $\mathrm{V}$ ao ocaso pombalino, privou com importantes figuras dos cenários político e mercantil lisboeta, manteve relações com grandes homens de negócios da América, protagonizou acaloradas disputas judiciais e participou de inovações relacionadas ao trânsito de mercadorias entre as duas margens atlânticas. Atuou em um momento de significativas mudanças, não só na administração da monarquia, mas no cenário mercantil do Atlântico português. Apesar disso, o episódio dos navios-correio é quase desconhecido, e a participação de Peres de Sousa nos demais casos é tratada de modo marginal. Os poucos trabalhos que o abordaram, en passant, preocupam-se com outros aspectos que não a sua carreira ou o imbricamento de suas relações sociais (Ellis, 1969; Pesavento, 2013; Paz, 2015; Salvino, 2018). No entanto, a sua história, inclusive no que tem de atípica, ajuda a desvelar alguns dos mecanismos de funcionamento do mercado de contratos régios no período pombalino. Assim, este artigo, ao trazê-la para o rés do chão - no caso, o chão dos palácios lisboetas -, busca contribuir com o preenchimento de algumas lacunas nesse aspecto, ainda que permaneçam muitas questões ainda sem resposta.

É interessante para o estudo da carreira de qualquer homem de negócios o entendimento de sua posição no interior das redes de sociabilidade de que faz parte. ${ }^{1}$ Para resgatar um termo proposto por Tiago Gil, os candidatos a 
contratadores tinham de ocupar uma boa posição no "mercado relacional" tanto na praça de arrematação, quanto naquelas onde se dava a execução dos contratos (Gil, 2015, p. 428). Todavia, o interesse aqui não é por um estudo mais amplo dos relacionamentos de Peres de Sousa, e sim pelo emprego estratégico que ele fazia de um segmento de suas redes, localizado em Lisboa, em busca da consecução de seus próprios objetivos de enriquecimento e ascensão social.

Embora tenha sido personagem central na atividade da pesca das baleias durante mais de 30 anos, o que parece emergir de sua história é um "lobo dos salões" antes que um "lobo do mar". Sua carreira, nesse sentido, ilustra as possibilidades de ação no limitado mundo dos grandes contratadores, em que o acesso direto aos principais canais decisórios parece ter sido relevante. Para ingressar e se manter no rentável mercado de contratos régios, era necessário não só capital econômico, mas também um sólido capital social, tanto para a constituição das malhas de fiadores, procuradores e caixas, quanto para influenciar as autoridades durante o processo de arrematação e depois, em questões como a cobrança de dívidas e prorrogação de prazos, entre outras. ${ }^{2}$

"Rede social" é um conceito polissêmico que, na maior parte das vezes, transformou-se em uma quase catacrese, uma metáfora desgastada, esquecida de sua origem. No caso deste estudo, entende-se que as configurações das redes sociais assumem caráter estratégico ou tático em função de escopos específicos e de limitações próprias a cada caso, no interior de um dado mercado relacional. Indivíduos agem tendo em vista os recursos, os valores e as relações sociais em que estão imersos, em busca de maximizar ganhos, proteger interesses e minimizar perdas. Para tanto, buscam alianças, de acordo com estratégias que, além desses valores e recursos, consideram as expectativas de ação dos demais sujeitos (Barth, 1981, p. 32-60). Nesse sentido, pode ser profícua a distinção entre laço (lazo, em espanhol) e relação (relación), proposta por Michel Bertrand, o primeiro referente à "dimensão morfológica" da rede social e o segundo à ideia de intercâmbio ativo, ou seja, à "dimensão dinâmica” dela (Bertrand, 2009). Desse modo, se o mercado relacional for pensado como um conjunto de pontos (ou atores), virtualmente ligáveis entre si, há uma rede potencial quando se estabelecem laços entre eles, bem como uma rede ativa quando tais laços se transformam em relações, focadas em objetivos concretos.

A expressão "capital social", mencionada aqui ao lado de "capital econômico", foi popularizada, principalmente, a partir de seu uso por Pierre Bourdieu (1980) e James Coleman (1994). Embora não haja consenso em relação ao seu significado, o termo, geralmente, é pensado em função do posicionamento do indivíduo em suas redes sociais. ${ }^{3} \mathrm{O}$ conceito, em Bourdieu, tem 
índole fortemente instrumental, com ênfase na construção deliberada de vínculos que possam angariar benefícios. Bourdieu também ressalta a conversibilidade das diversas formas de capital, cujas configurações não monetárias - simbólicas e sociais - podem resultar em recursos econômicos e financeiros como fruto de estratégias bem desenvolvidas. Coleman, por sua vez, estabeleceu uma distinção entre as fontes do capital social (os que podem fornecer os recursos), os seus possuidores (os que solicitam os recursos) e os recursos propriamente ditos. O capital social corporifica-se na capacidade de aceder a esses recursos. Na acepção de Coleman, de modo geral, quanto mais densas as redes (ou seja, quanto maior a quantidade de conexões permitidas), maiores as possibilidades de constituição do capital social. Essa visão foi matizada pelos estudos de Burt (2007), que destacou um aspecto qualitativo ou topológico das redes, ao colocar em cena o papel dos "buracos estruturais" (structural holes), configurações em que um agente (por ele chamado de broker) assume uma posição privilegiada por ser a ligação entre partes diferentes de uma determinada rede - papel semelhante ao desempenhado por Peres de Sousa nos primeiros anos de sua carreira, quando há indícios de ter servido de ponte, no caso do contrato das baleias, entre homens de negócios do Brasil, como João Hopman e Manuel Luís Vieira, e os centros decisórios em Lisboa.

Neste artigo, o capital social é visto como um fator que só adquire significado no âmbito das redes de sociabilidade, como a capacidade e a possibilidade do sujeito de acessar e ativar recursos nelas disponíveis em função de determinados objetivos. Essa visão instrumental aproxima-se da concepção de Bourdieu, aqui lembrada, mas também das ideias de Barth (1981), na medida em que a ativação das alianças é fruto de ações estrategicamente concebidas, em um jogo do qual participam diversos sujeitos. Nos empreendimentos de Peres de Sousa, envolveram-se indivíduos radicados em várias praças ultramarinas, tanto em atividades operacionais, quanto na arquitetura e na viabilização financeira dos negócios. Entretanto, a proximidade com o centro de poder em Lisboa foi crucial, não só para a obtenção de seus contratos, mas para que ele continuasse a participar da administração ou, pelo menos, do lucro deles, até a sua morte em 1782, mesmo diante de uma série de percalços. Como se verá, os sinais são de que Peres de Sousa valia-se de sua proximidade com figuras como o marquês de Pombal e Inácio Pedro Quintela - talvez com o próprio José I - para se manter à tona no complexo mercado de contratos régios. Há indícios até de que os recursos financeiros que utilizou nesses negócios tenham sido angariados, ao longo dos anos, pelo hábil manejo de suas relações na Corte e no ultramar. O estudo de sua inserção no núcleo de poder 
lisboeta é o foco deste artigo, que não se debruçará, portanto, sobre o funcionamento e a articulação de suas redes nos clusters ultramarinos.

\section{DE PROFESSOR DE MÚSICA A CONTRATADOR DE DIREITOS RÉGIOS}

As informações sobre Francisco Peres de Sousa são bastante lacunares. Como se verá, sabe-se que ele morreu no princípio de 1782, acumulou bens consideráveis e teve relacionamento bastante próximo com dois sobrinhos, seus únicos herdeiros. Contudo, não houve como apurar o local e o ano de seu nascimento. Não foram encontrados, até agora, sinais dele em pedidos de mercês e nas habilitações do Santo Ofício. As fontes sinalizam que começou sua carreira de maneira atípica. Em meados dos anos 1740, propôs criar um sistema de navios-correio (paquetes ou paquebotes, no português da época) entre Lisboa e os principais portos brasileiros (Rio de Janeiro, Bahia e Pernambuco), de modo a garantir um fluxo regular de correspondências, por meio de viagens bimestrais. Na ocasião, o secretário e conselheiro do Conselho Ultramarino Manuel Caetano Lopes de Lavre acusou-o de não ter "nem prática, nem cabedais para semelhante arbítrio porque há poucos anos o conheceu ele Conselheiro ensinando solfa, e cravo, em várias casas particulares desta Corte"4 - informação confirmada no mesmo processo por Alexandre de Gusmão. Trata-se de um ofício estranho ao percurso habitual dos homens de negócios, que, independentemente de atividades anteriores, iniciavam, muitas vezes, a sua carreira mercantil a trabalhar para outros comerciantes, às vezes dentro do círculo de suas relações familiares. Nessas ocasiões, aprendiam as artes e as manhas de seu métier (Pedreira, 1992).

No caso dos navios-correio, o cravista apresentou-se como assistente do correio-mor no estado do Brasil, qualificativo que não o vimos mais invocar nos anos seguintes, sinal de não deve ter chegado a exercer de fato o ofício, em decorrência do fracasso do projeto. Para obter a concessão, comprometia-se a fazer um donativo anual de 10 mil cruzados ao Hospital Real, motivo por que a demanda foi encaminhada pelo administrador daquela entidade, o enfermeiro-mor. Para financiar a operação, as embarcações transportariam sal e fazendas molhadas do Reino para o Brasil e voltariam carregadas com produtos da terra, sendo vedado o transporte de fumo, de ouro e de pedrarias a qualquer título. Essa arquitetura devia facilitar a montagem da malha logística, ao permitir a vários armadores e comerciantes participarem do negócio. O transporte de sal exigia o aval do contratador daquele estanco, Estevão Martins Torres, que, assim como o correio-mor, apresentou parecer favorável ao arranjo. 
Os rendimentos de um organista em Lisboa, na década de 1740, eram, em média, inferiores a 17 mil réis anuais. ${ }^{5}$ Não deviam fugir muito disso os ganhos de um cravista ou professor de solfa, ainda que pudesse haver variações em função da clientela atendida. Assim, devia causar estranheza um indivíduo desse meio propor um negócio que pressupunha a movimentação de muitos contos de réis. Esse início incomum, entretanto, provavelmente facilitou a ampliação das redes de influência de Peres de Sousa no mercado relacional da Corte, ao colocá-lo em contato direto com as famílias de autoridades e comerciantes, inclusive ingleses, que compunham uma considerável colônia na capital portuguesa.

O conselheiro e secretário Caetano Lopes de Lavre, bem como os representantes da Confraria do Espírito Santo, acusaram-no de ser mero testa de ferro dos ingleses, que já haviam tentado implantar negócio semelhante anos antes. Alexandre de Gusmão, veemente defensor do projeto dos navios-correio, fez pouco dessa acusação, ao perguntar "quem entre todos os comerciantes de Lisboa, o que faz o comércio do Brasil com cabedal seu e sem depender dos estrangeiros??. ${ }^{6}$ Os vogais da Confraria, além de apontarem Peres de Sousa como sem fundos próprios para a empreitada, acoimaram-no de inexperiente e apresentarem diversos senões ao projeto em si, acusando os paquetes de desnecessários, danosos ao comércio e facilitadores do contrabando. Eram opositores de peso, pois, desde a década de 1720, a Mesa do Bem Comum do Comércio, integrada por elementos da Confraria, assumira importante papel na formulação das políticas comerciais, ao mesmo tempo como órgão consultivo informal da coroa e como entidade de defesa dos interesses dos negociantes. O certo é que, apesar da defesa de Gusmão e de ter obtido a maioria dos votos favoráveis entre os membros do Conselho Ultramarino, depois de delongar-se por anos, o projeto dos navios-correio foi arquivado em 1749. A história desse fracasso, contudo, ilustra já o que parece ter sido o modus operandi de Peres de Sousa nos anos seguintes, ao aliar-se a vários homens de negócios e membros da nobreza. No caso, não se descarta ter sido ele um misto de articulador e de testa de ferro de outros atores, cada um deles guiado por seus interesses particulares, a valer-se de sua facilidade de circulação entre homens de grosso trato e autoridades para atingir seus próprios objetivos.

Peres de Sousa não ganhava a vida só com as aulas de música. No mesmo processo dos navios-correio, Alexandre de Gusmão informa que o futuro contratador estivera pouco antes no Rio de Janeiro como tesoureiro dos defuntos e ausentes (Requerimento, 1745). O fato de aquele ofício ser de provimento régio indicia que Peres de Sousa já tivesse naquele momento certo grau de 
influência e mobilidade, ainda que se tratasse de um cargo menor da administrativa portuguesa. Além disso, a viagem ao Brasil pode ter-lhe facilitado criar relações no ultramar, algo desejável para a sua futura atividade como contratador. Durante esta pesquisa não se conseguiu apurar quanto tempo ele teria ficado de fato naquela cidade; porém, enquanto corria o processo dos paquetes, em 1748, alguém com o nome de Francisco Peres de Sousa também foi nomeado escrivão da ouvidoria e tabelião da Vila de Cuiabá. Poderia ser um homônimo do personagem aqui estudado, mas não se pode descartar serem a mesma pessoa. Havia impedimento de ambas as funções serem atribuídas a um mesmo indivíduo, mas um despacho régio dispensou o cumprimento de tal exigência, "com declaração que [os ofícios] serão servidos por diversas pessoas". ${ }^{7}$

Assim, até o final da década de 1740, nosso personagem teve de se contentar com postos de pouca relevância na administração periférica portuguesa, sem conseguir negócios de maior vulto. Em 1750, todavia, José I assumiu a coroa. Com a mudança, Alexandre de Gusmão, simpático a Peres de Sousa no caso dos paquetes, foi para uma posição periférica e faleceu pouco tempo depois. Nos anos seguintes, ganharia relevo o ministro Sebastião José de Carvalho e Melo, futuro conde de Oeiras e marquês de Pombal, figura de proa durante todo o reinado de José I. Esse período é bastante estudado, com visões muitas vezes discordantes sobre o papel de Carvalho e o significado de sua administração. Mas, independentemente de divergências interpretativas, há de se ressaltar grandes mudanças na condução da esfera que hoje chamamos econômica, seja como fruto de uma intervenção mais programática, seja como resultado de ações casuísticas. Interessa aqui lembrar a criação da Junta de Comércio, do Erário Régio e das companhias mercantis, um núcleo de gestão em torno do qual se buscou reunir um grupo de fortes homens de negócios, capazes de concorrer com as grandes casas comerciais europeias.

Poucos anos depois da ascensão de Carvalho, em 1755, a Confraria do Espírito Santo, que tanta desconfiança mostrara em relação ao cravista, foi extinta por ação do ministro, entre outros motivos, por causa da oposição às novas companhias de comércio, ocasião em que alguns de seus principais membros chegaram a ser presos e degredados e a sua ação foi substituída pela nova Junta de Comércio. ${ }^{8}$ Nesse quadro, segundo Kenneth Maxwell (1996, p. 74), um dos "instrumentos mais importantes utilizados por Pombal para promover a formação de capital entre os comerciantes portugueses era o arrendamento de contratos reais" - e Peres de Sousa foi um dos que souberam se 
aproveitar dessa circunstância, embora não tenha chegado a constar no topo da elite mercantil.

As mudanças implementadas no período pombalino tiveram impacto tanto no Reino quanto no ultramar, onde o Rio de Janeiro teve fortalecido o seu papel de principal praça econômica do Brasil e do Atlântico Sul, em um processo iniciado várias décadas antes e que culminou na mudança da capital do vice-reinado para aquela cidade em 1763. Nesse quadro, as redes constituídas pelos homens de negócios tiveram papel crucial, inclusive na gestão dos contratos régios. Conforme destacado por Pesavento e Guimarães (2013, p. 81-87), fortaleceu-se nesse período um grupo de homens de grosso trato que, apesar de moradores da praça carioca, participavam de redes cujas malhas estendiam-se, às vezes, além das fronteiras da monarquia ultramarina. Componentes desse grupo arremataram parte significativa dos contratos régios e participaram, como procuradores, administradores locais ou sócios, da gestão de outros, encabeçados por negociantes baseados no Reino. Peres de Sousa manteve vários interesses nesse mercado, sem deixar Lisboa, a não ser para viagens esporádicas. Encabeçou a arrematação de alguns contratos de grande valor ou teve participação societária de vulto em outros, atuando como uma espécie de broker entre o centro de poder lisboeta e os agentes baseados não só naquela praça brasileira, mas também na Bahia e em vários locais das capitanias do sul.

Há evidências de que o músico soube aproximar-se do novo círculo de poder em torno do futuro marquês de Pombal ainda na primeira metade da década de 1750, ao passo que antigos contratadores perdiam lugar. Para isso pode ter contribuído uma forma incomum de criar proximidade com o ministro. Muitos anos depois, em 1777, já durante o início do governo de Maria I, um de seus principais desafetos, Tomé Gomes de Sá, em processo no qual procurava garantir para si o contrato da pesca das baleias no Brasil, acusou Peres de tê-lo prejudicado, aproveitando-se da posição de "mestre de cravo na casa de Pombal", e de que "se valera da política de malquistar na presença de Sua Majestade", para o "fazer prender e sequestrar enquanto obtinha a prorrogação do contrato [das baleias] por doze anos, pondo na cabeça dele, homem de mais crédito e melhor nome, e usando da poderosa proteção do Marquês". ${ }^{9}$ Tais palavras aparentemente visavam intrigar o oponente junto ao novo círculo de poder, em um momento em que Pombal acabara de ser afastado de seu cargo. São indício de que o músico, mesmo depois de assentado como homem de negócios, continuava a valer-se de sua atividade como professor particular para fazer negócios nos salões lisboetas. 
Em 1753, já o vamos encontrar como arrematante, por 3 anos (17541756), dos contratos dos subsídios grandes e pequenos dos vinhos e da aguardente do Rio de Janeiro, pelos valores anuais de 10 contos e 600 mil réis o primeiro e 5 contos e 200 mil réis o segundo, sem a presença de outros sócios declarados. De acordo com o exposto por Tomé Gomes Moreira em uma de suas petições contra Peres de Sousa, o contrato teria sido repassado a Caetano do Couto Pereira, personagem recorrente no cenário das arrematações de direitos e tributos. $\mathrm{O}$ caminho percorrido por essa contratação teve algumas peculiaridades, que indicam influência direta da Coroa. Um aviso régio determinou que se suspendesse um processo em curso no Conselho Ultramarino, logo seguido por um decreto que ordenou a arrematação posterior desses contratos a Francisco Peres de Sousa, em 7 de maio de $1753 .{ }^{10}$

Também em 1753, o contratador das baleias da Bahia, João Francisco, que assumira a avença em outubro do ano anterior, cedeu-a por 6 anos a Peres de Sousa, por 12 contos e 980 mil réis anuais. ${ }^{11} \mathrm{O}$ fiador no caso era o mesmo Caetano do Couto Pereira. Assim, naquele momento, o cravista, que havia menos de uma década era acusado de não ter cabedais, já se encontrava, pelo menos nominalmente, à testa de contratações que montavam mais de 28 contos anuais.

Mas não parariam aí os seus avanços. No ano seguinte, arrematou também os contratos de pesca das baleias do Rio de Janeiro, Ilha de Santa Catarina, São Sebastião, Santos e São Paulo, pelo período de 6 anos a contar de 1755 (Contratos, 1755). O ato marcou a sua entrada em um mercado no qual teria participação bastante ativa nas décadas seguintes. O processo de arrematação, todavia, foi bastante nebuloso. Desde 1743, o contrato das baleias do Rio de Janeiro estivera nas mãos da família Gomes Moreira. Primeiro nas de Tomé, um comerciante português radicado naquela cidade, e depois nas de seu filho Pedro, morador de Lisboa, que assumiu a avença a partir de 1748, embora, segundo os documentos existentes, o verdadeiro dono do negócio continuasse sendo seu pai.

Em 1753, Pedro Gomes Moreira voltou a ganhar a contratação, válida a partir do ano seguinte, com o valor de 48 mil cruzados e 100 mil réis anuais, tendo como fiador o quase onipresente Caetano do Couto Pereira. Assim que pagou as propinas devidas, deslocou-se para o Rio de Janeiro com Peres de Sousa, que teria um quarto do contrato. Entretanto, o velho Tomé, que se dizia dono integral do negócio, estava alheio a qualquer tratativa nesse sentido. Quando teve ciência dos boatos a respeito, eles teriam sido negados diante de um crucifixo por Pedro, que faleceu em seguida, de causas ignoradas. Em 
seguida, a provedoria do Rio de Janeiro impediu que Tomé Gomes Moreira assumisse o negócio, pois seria devedor de algumas parcelas de outros arrendamentos, em um montante de mais de 50 contos. Também não foi paga a fiança do contrato, que se deveria quitar naquela localidade, nem se publicou o alvará de correr, requisito formal para que se fechasse o processo de contratação. Assim, sem que houvesse nova licitação, Francisco reivindicou a avença, a pretexto de sua condição de sócio. Alegou não ser devedor da Real Fazenda e que não poderia ser prejudicado pelas dívidas de Tomé. Em sua petição consta haver uma "justificação inclusa" que provaria sua condição de interessado no contrato, mas não existe nenhum papel com essa finalidade nos autos até agora pesquisados, assim como não foi encontrada cópia de uma possível escritura de cessão da avença de Pedro para Tomé. O certo é que o contrato terminou adjudicado a Peres de Sousa pelo mesmo valor e com as mesmas condições do pleito anterior, que foi anulado. ${ }^{12}$

Tomé Gomes Moreira, sentindo-se traído, reagiu em defesa daqueles que julgava ser seus direitos. Quase três décadas depois, seus herdeiros ainda pediam o bloqueio do espólio de Peres de Sousa em função da pendenga. Apesar desses protestos, a contratação não só continuaria com o professor de música, mas seria estendida até 31 de março de 1765. O contrato continuava a apresentar como fiador Caetano do Couto Pereira, que morreria algum tempo depois. Documentos posteriores afirmam terem também exercido esse papel Antônio Martins da Costa e Bento Gonçalves Fortes. ${ }^{13}$

É interessante observar a onipresença de Caetano do Couto Pereira em todas as movimentações contratuais aqui relatadas, acontecidas entre $1753 \mathrm{e}$ 1754. Seus irmãos, João e José do Couto Pereira, seriam depois administradores e sócios do contrato das baleias no Rio de Janeiro. Não se descarta, assim, que Peres de Sousa fosse, pelo menos de início, testa de ferro dos Coutos Pereiras. Mas ainda que se desconheça em pormenores a real participação de cada um desses indivíduos na arquitetura do empreendimento, não se deve minimizar a função desempenhada pelo cravista, seja pela sua participação ativa em vários atos contratuais nos anos seguintes, seja pela sua manutenção no negócio anos depois, quando ele trocou de mãos, como se verá.

Em 1759, Peres de Sousa prorrogou também o contrato das baleias da Bahia, pelos mesmos 32.450 cruzados anuais, igualando seu tempo de vigência ao do Rio de Janeiro. Desse modo, tornou-se o primeiro indivíduo a ter em suas mãos a pesca dos cetáceos em toda a costa brasileira. Graças a uma ordem régia de 1760, o músico conseguiu também autorização para enviar, fora das frotas, barcos para o transporte exclusivo de óleo e barbatanas entre o Brasil e 
o Reino, até um limite de 600 toneladas. Assim, logrou, por outros caminhos, algo que tentara em vão em 1745, ou seja, estabelecer um circuito de navegação entre os dois lados do Atlântico, independente do fluxo principal. ${ }^{14}$

\section{A SOCIEDADE COM OS QUINTELAS}

Mas nem tudo eram alegrias. No início de 1764, aconteceram sérios problemas na Bahia. A produção das armações daquela região encontrava-se em franca decadência, em consequência de fatores naturais ou da ação predadora dos baleeiros. Além disso, João Vieira Torres, o administrador local, foi acusado de dever à Fazenda Real quase 20 contos de réis, o correspondente a quase um ano e meio de pagamentos contratuais. Em plena crise, Vieira Torres foi substituído por Joaquim Caetano do Couto, que veio pela frota daquele ano com novas ordens. Todavia, pouco antes da chegada dos navios, em 8 de maio de 1764, a Junta da Fazenda local determinara que todos os bens do contratador na Bahia fossem sequestrados, contra o parecer do Provedor, em episódio com fortes indícios de refletir disputas locais. ${ }^{15}$

A troca do administrador, contudo, não fora um ato isolado. Enquanto a crise se desenrolava, a pesca das baleias em toda a costa brasileira foi arrematada, em 6 de julho de 1764, a Inácio Quintela e Companhia, sociedade constituída especialmente para essa finalidade. A data em que isso aconteceu indica que, quando Joaquim Caetano do Couto partiu para a Brasil, a solução já estava, se não concertada, pelo menos em andamento. Segundo uma carta de Joaquim Pedro Quintela, sobrinho e sucessor de Inácio Pedro, datada de mais de 20 anos depois dos acontecimentos, os primeiros passos para a criação dessa entidade mercantil tinham sido dados em 1763, quando o tio fora procurado pelo marquês de Pombal para capitanear uma mudança no negócio das baleias, a ser reorganizado nos mesmos moldes das demais companhias pombalinas. Tal data pode estar equivocada, mas de qualquer modo é um indicativo de que a ideia da sociedade começou a germinar um bom tempo antes de sua implantação.

Inácio Quintela era figura central em diversas ações do governo português na época. Foi provedor da Junta do Comércio, diretor das Companhias do Maranhão e Grão-Pará e de Pernambuco e Paraíba, acionista da fábrica de Lisboa e grande exportador (Maxwell, 1996, p. 149). Teve participação direta em diversos contratos de rendas e direitos régios no Brasil, como os do tabaco e do sal. Aceitou tomar a frente da companhia de pesca das baleias, mas, em um primeiro momento, outros negociantes resistiram a aderir ao empreendimento, preocupados com os riscos e com a grandes quantias envolvidas. ${ }^{16} \mathrm{O}$ 
fato de as Condições Particulares, documento destinado a regular a administração do negócio, serem datadas de fevereiro de 1765, mais de 6 meses depois do início do contrato, pode ser indício de improvisos na solução final, apesar do longo tempo de gestação do negócio (Silva, 1844, p. 76-79). Parece significativo também que a constituição de fato da sociedade tenha ocorrido quando dos problemas na Bahia, ou seja, as disputas ali acontecidas, tanto quanto o término do contrato anterior, podem ter precipitado a solução adotada.

A nova empresa teve uma estrutura bem mais modesta do que a das principais companhias pombalinas e um conjunto de apenas oito investidores. Além de Quintela e de Francisco Peres de Sousa, que permaneceu no negócio, entraram como sócios diversos agentes com participação importante em outras companhias ou que se notabilizaram por assumir outros grandes contratos régios. José Alves Bandeira e João Fernandes Vieira, por exemplo, são conhecidos como contratadores, respectivamente, do tabaco e dos diamantes. Além deles, António dos Santos Pinto, Francisco José da Fonseca, João Fernandes de Oliveira, Domingos Dias da Silva e Baltazar dos Reis completaram o grupo. ${ }^{17}$

É difícil afiançar qual o papel exercido pelo cravista na articulação da nova sociedade. Inácio Quintela era homem da confiança do então conde de Oeiras, futuro marquês de Pombal, mas talvez não tivesse chegado aos negócios baleeiros não fossem gestões do músico. Como já mencionado, muitos anos depois, o neto de Tomé Gomes Moreira o acusaria de aproveitar-se da posição de mestre de cravo na casa do poderoso ministro para obter a prorrogação do contrato por 12 anos, "pondo na cabeça dele homem de mais crédito e melhor nome". Embora essa afirmativa tenha vindo de um desafeto do músico, interessado em prejudicá-lo junto a Maria I, não deixa de ser um sinal de sua atuação na urdidura do feito. O negociante francês Jerome Ratton, contemporâneo dos eventos, chegou a afirmar que "criou o governo em Lisboa uma Companhia para a pesca da baleia, nas costas do Brasil, sobre um certo fundo que já existia, cuja origem ignoro; mas sei que a principal parte pertencia a Peres, tio de dous outros Peres" (Ratton, 1843, p. 243, grifo meu). Myriam Ellis e Marcelo de Oliveira Paz aventaram a hipótese de o fundo mencionado por Ratton ser composto por ativos e passivos dos antigos contratos de Peres de Sousa. Embora gravados pela dívida, o cravista tinha bens de capital e estoques do Rio de Janeiro para garantir a sua entrada na nova sociedade. Contudo, não é certo que a principal parte pertencesse a Peres. $\mathrm{O}$ documento que regula $\mathrm{o}$ funcionamento da companhia não esclarece a parcela de cada sócio no capital dela. Todavia, um ofício emitido anos depois afirma que, embora o montante devesse ser dividido em oito partes iguais, Domingos Dias da Silva e José Alves 
Bandeira, tomados de "repugnância", somente aceitaram ficar com um 16 avos cada qual. Francisco José da Fonseca, futuro administrador no Rio de Janeiro, teria assumido então a cota faltante, tornando-se o possuidor da maior parcela do capital. ${ }^{18}$

Uma série de medidas contribuiu para fortalecer a contratação, bem como eliminar riscos de problemas semelhantes aos da Bahia, ao colocar o negócio mais diretamente sob a proteção régia. Por exemplo, no caso de atrasos de pagamentos, os provedores da Fazenda deviam mandar os papéis relativos à dívida para Lisboa, o que excluiu a administração periférica da Coroa das decisões relativas a essas questões. A dinâmica dos pagamentos a serem realizados pelos contratadores foi esclarecida nas Condições Gerais do Contrato, de modo a evitar interpretações particularizadas. O decreto de 12 de fevereiro de 1765, ao determinar que a arrematação seria feita na Secretaria de Estado dos Negócios da Marinha e Domínios Ultramarinos, retirou o assunto da alçada do Conselho Ultramarino e o trouxe para um círculo mais próximo do conde de Oeiras e do próprio rei. Não por acaso a ordem se encerrava reservando "tudo o que pertence a este Contrato e suas Condições a Meu Real e imediato conhecimento”. E não parariam nesse ponto as benesses concedidas. Um alvará de 10 de setembro daquele mesmo ano autorizou os contratadores da pesca da baleia a transportar qualquer gênero da Bahia para Lisboa, o que contribuía para aumentar a lucratividade do negócio e antecipou, na prática, a liberdade trazida pelo fim do sistema de frotas, somente aprovado no ano seguinte. ${ }^{19}$

Na nova companhia, as funções de maior relevo foram de Inácio Pedro Quintela e Francisco José da Fonseca, respectivamente caixa geral e administrador no Rio de Janeiro. Com o novo desenho da atividade, diminuiu ou mesmo cessou a presença da família Couto Pereira no negócio. Segundo as Condições Particulares que regulavam o funcionamento da sociedade, embora as principais decisões devessem ser tomadas de forma colegiada, o voto de Minerva cabia a Inácio Pedro, bem como as providências de caráter mais urgente. Desse modo, pelo menos oficialmente, Peres de Sousa passou para um segundo plano na gestão do contrato. Todavia, com a solução adotada ele continuou a participar de arrematações de contratos de vulto, mesmo depois do imbróglio da Bahia. Permaneceu com meios para pagar suas dívidas, e o negócio ganhou novos aportes e facilidades. Assim, há elementos bastantes para dizer que o cravista, independentemente da posição formal que ocupou na nova sociedade, foi favorecido pela solução adotada.

Durante os anos seguintes, foram várias as ocasiões em que ficou claro o bom trânsito de Quintela e seus sócios com a Coroa, em negócios de que 
Francisco Peres de Sousa se beneficiou com demais integrantes da sociedade. Em 1768, por meio de um contrato com vigência de 6 anos contados a partir de $1^{\circ}$ de janeiro de 1770 , a companhia arrematou o estanco do sal do Brasil, pelo valor de 106 mil cruzados anuais (Contrato, 1768). Mais uma vez a contratação não resultou de um processo licitatório, mas de um decreto régio. $\mathrm{Na}$ ocasião, argumentou-se que os dois negócios - baleias e sal - eram complementares, pela necessidade de salgar parte dos produtos da atividade baleeira, mas tal alegação seria acusada ao longo dos anos de ser mero subterfúgio para justificar a amarração entre contratos muito diferentes, tanto por parte dos herdeiros de Tomé Gomes Moreira quanto por Domingos Lopes Loureiro, nos mesmos processos que serão várias vezes mencionados neste trabalho.

Em maio de 1774, em mais um indício do poder de fogo de seus arrematantes, o contrato das baleias foi prorrogado por 12 anos, a contar de abril de 1777, uma antecedência não usual. Um alvará emitido na mesma ocasião confirmou que tudo relativo à avença ficava reservado ao imediato conhecimento régio. ${ }^{20}$ No mesmo mês, o contrato do sal também foi concedido de novo à companhia, com vigência a partir de $1^{\circ}$ de janeiro de 1776, por mais 6 anos, mantido o valor da avença em curso. ${ }^{21}$ Essas movimentações chamam ainda mais a atenção quando se constata que, em 1774, o rei, que já sofrera uma primeira apoplexia em 1769, apresentou sérios problemas de saúde (Maxwell, 1996, p. 159). Uma hipótese não descartável é de esses adiantamentos das contratações obedecerem a um desejo dos contratadores de preservarem seu monopólio diante dos riscos de uma possível troca de poder na monarquia.

Nesse meio tempo, a proximidade de Peres com Inácio Pedro Quintela ia além dos contratos régios. Com o padre italiano Giuseppe Galli e o homem de negócios António Soares de Mendonça, ambos foram diretores da Sociedade para a Subsistência dos Teatros Públicos da Corte, formada em 1771, a pedido de um grupo encabeçado pelo marquês de Pombal. A sociedade foi constituída com um capital de 100 mil cruzados, repartidos em ações de 400 mil réis. Entretanto, apesar de sua importância para a cena teatral lisboeta, materializada na produção de várias montagens com artistas italianos, a companhia não parece ter-se revelado rentável. Em março de 1773, seus diretores pediram um empréstimo de 6 contos de réis ao Senado da Câmara para suprimento das despesas dos teatros, haja vista a insuficiência das entradas. ${ }^{22}$ Em 1776, acabaria dissolvida.

No ano anterior, falecera Inácio Quintela. Antes disso, já haviam morrido dois sócios da Companhia da Pescaria das Baleias, João Fernandes de Oliveira (em 1770) e Antônio dos Santos Pinto (em data não apurada). As vagas dos dois na sociedade foram ocupadas por Joaquim Pedro Quintela, sobrinho de Inácio, 
e José do Couto Pereira, que já vimos antes como administrador do contrato no Rio de Janeiro. Joaquim Pedro é quem assumiu o caixa da companhia quando da morte do tio, sem contestações. Contudo, a já aqui mencionada renovação antecipada do contrato por mais 12 anos, acontecida em 1774, daria início a uma crise. Segundo reclamação apresentada ao marquês de Pombal por Francisco José da Fonseca, o então administrador no Rio de Janeiro pretendia colocar como partes minoritárias da sociedade Luís Antônio Tinoco, guarda-livros no Rio de Janeiro, e João Marcos Viana, administrador da armação de Santa Catarina, para recompensá-los por seu trabalho e retê-los em seus postos. Para tanto, dividiria entre eles o oitavo do contrato a mais que assumira quando da constituição da sociedade. Os demais sócios, todavia, preferiram redistribuir esse valor para Domingos Dias da Silva e José Alves Bandeira, que o haviam rejeitado no momento da primeira contratação, quando o negócio ainda se cercava de problemas e incertezas, solução que provocou a revolta de Fonseca. Os papéis relativos a esse caso, assim como outros, sinalizam que, naquele momento, pelo menos formalmente, Francisco Peres de Sousa estava em posição secundária quando se tratava das principais decisões do contrato, pois todas as reclamações de Fonseca referem-se a decisões atribuídas principalmente aos Quintelas.

Enquanto o imbróglio estava pendente de decisão, houve uma mudança substancial na política portuguesa. Em novembro de 1776, José I sofreu uma apoplexia, e a regência foi assumida novamente pela rainha D. Mariana Vitória de Bourbon. Em fevereiro do ano seguinte, faleceu o rei. Pouco depois de subir ao trono, em março, Maria I, a nova rainha, depôs Pombal e nomeou um novo gabinete. $\mathrm{O}$ afastamento do antigo ministro animou forças contrárias à sua gestão em diversas frentes, inclusive no que se refere ao contrato da pescaria das baleias. Além de os descendentes de Tomé Gomes Moreira terem recrudescido suas investidas, Domingos Lopes Loureiro, morador de Lisboa, peticionou junto ao Conselho Ultramarino para que o negócio lhe fosse concedido, com a oferta de um terço a mais do valor pago por Quintela e seus sócios. ${ }^{23}$ Francisco Peres de Sousa foi sempre a figura mais atacada, sob a acusação de se ter aproveitado de sua amizade com o antigo ministro para as suas manobras. É provável que isso não decorresse apenas de uma ojeriza pessoal, mas obedecesse a uma estratégia jurídica de estabelecer continuidade histórica entre os vários contratos. Tendo em vista os objetivos específicos deste artigo, não interessa, porém, desenvolver aqui o estudo desses pleitos, mas apenas destacar a turbulência do momento.

A despeito desses problemas, os Quintelas e seus sócios continuaram com bom trânsito junto à nova administração. Em janeiro, um decreto régio anulou a participação de Fonseca nos contratos das baleias e do sal, com a alegação de 
que, no momento oportuno, ele não manifestara sua intenção de se manter na sociedade. Domingos Mendes Viana assumiu o seu lugar, inclusive como administrador do contrato no Brasil. Tentativas posteriores de reverter a situação foram ignoradas. ${ }^{24}$

Além de se manter no contrato das baleias, Peres de Sousa participou, mais uma vez, em 1781, da contratação, por 114 mil cruzados anuais, do estanco do sal do Brasil, em sociedade com Joaquim Pedro Quintela, Jacinto Fernandes Bandeira e João Batista da Silva, por um período de 6 anos, a contar do início do ano seguinte. ${ }^{25}$

O resumo dos vários contratos de que participou Peres de Sousa pode ser visto na Tabela 1.

Tabela 1 - Contratos com participação de Francisco Peres de Sousa no Brasil

\begin{tabular}{l|c|c}
\hline \multicolumn{1}{c|}{ Contrato } & Período & $\begin{array}{c}\text { Valor anual } \\
\text { (contos de réis) }\end{array}$ \\
\hline $\begin{array}{l}\text { Subsídios grandes e pequenos dos vinhos e da } \\
\text { aguardente do Rio de Janeiro }\end{array}$ & $1754-1756$ & 15,80 \\
\hline Pesca das baleias da Bahia & $1753-1764$ & 12,98 \\
\hline Pesca das baleias da Bahia & $1759-1764$ & 15,57 \\
\hline $\begin{array}{l}\text { Pesca das baleias do Rio de Janeiro, Ilha de Santa } \\
\text { Catarina, São Sebastião e Santos }\end{array}$ & $1754-1765$ & 19,30 \\
\hline $\begin{array}{l}\text { Pesca das baleias nas costas do Brasil (como } \\
\text { sócio de Inácio Pedro Quintela e Companhia) }\end{array}$ & $1765-1777$ & 38,40 \\
\hline $\begin{array}{l}\text { Pesa das baleiras nas costas do Brasil (como } \\
\text { sócio de Joaquim Pedro Quintela e Companhia) }\end{array}$ & $1777-1789 *$ & 40,00 \\
\hline $\begin{array}{l}\text { Estanco do sal do estado do Brasil (como sócio } \\
\text { de Joaquim Pedro Quintela e outros) }\end{array}$ & $1770-1782$ & 42,40 \\
\hline $\begin{array}{l}\text { Estanco do sal do estado do Brasil (como sócio } \\
\text { de Joaquim Pedro Quintela e outros) }\end{array}$ & $1782-1789 *$ & 45,60 \\
\hline
\end{tabular}

Fontes: AHU_ACL_CU_17, cx. 103, D. 8762; AHU_ACL_CU_003, cx. 14, D. 1225; AHU, Bahia, cx. 35, doc. 6735; cx. 108, doc. 42; cx. 161, doc. 27; cx. 160, doc. 21; AHU, Contratos do Sal, Códice 306; AHU, Contratos do Sal, cx. 1, doc. 75 e 76; AHU, Rio de Janeiro, cx. 53, doc. 64; cx. 56, doc. 40; cx. 57, doc. 27 ; cx. 67 , doc. 47 ; cx. 110 , doc. 67 ; cx. 111, doc. 12 ; cx. 129, docs. 43, 35, 45; cx. 137, doc. 24; cx. 144, doc. 62; AHU, RJ-avulsos, cx. 102, doc. 8749; cx. 104, docs. 881, 8797; AHU, São Paulo, caixa 25, doc. 2419; CONTRATO, 1768; CONTRATO, 1782.

${ }^{*}$ ) Peres de Sousa faleceu no início de 1782, durante a vigência desses contratos. 
Caso se considere a soma dos contratos em suas mãos, nos meados dos anos 1750 ele já estava nominalmente à frente de negócios de várias dezenas de contos de réis anuais com a Coroa. Não se encontraram dados sistemáticos de quais poderiam ser os rendimentos dessas avenças ou de que qual seria a efetiva participação do cravista na composição dos capitais envolvidos, mas é possível constatar uma sólida evolução das empreitadas de que participou até o final de sua vida.

Mas, se tudo corria bem com os negócios, fantasmas do passado não deixavam de assediá-lo. Como vimos, os herdeiros de Tomé Gomes Moreira continuavam a acioná-lo judicialmente, bem como à Coroa, acusando-o de ter obtido ilicitamente o contrato das baleias. Pediam a reparação de prejuízos e lucros cessantes, bem como o embargo dos bens do desafeto, como garantia da causa. Em abril de 1782, os litigantes solicitaram urgência do arresto, pois Peres de Sousa estava muito doente e já recebera a extrema unção. ${ }^{26}$ Seus sobrinhos estariam a dissipar sua fortuna. O pedido foi inicialmente acatado pelo procurador da Fazenda no Conselho Ultramarino, mas a ordem foi logo derrubada por determinação da rainha, a quem tinham recorrido os herdeiros do músico. ${ }^{27}$

$\mathrm{Na}$ realidade, Peres de Sousa não chegou a auferir os ganhos referentes ao novo contrato do sal, pois morreu no início de 1782. Naquele momento, tinha interesses documentados em contratos com a Coroa cujos valores montavam a mais de 80 contos anuais. Ao morrer, era homem de razoáveis posses, parte das quais registrada em um inventário de cerca de 180 páginas, datado de 2 de março de $1782 .{ }^{28}$ Bastante minucioso ao descrever miuçalhas, o documento não menciona, contudo, a participação nos contratos das baleias e do sal nem aponta valores de alguns bens de maior vulto, como a própria casa em que morava o contratador. Quando de sua doença e morte, boatos davam conta que cerca de 40 contos de réis em dinheiro vivo já teriam sido repassados para seus sobrinhos. ${ }^{29}$ Apesar da dificuldade em precisar seu patrimônio, uma notável evolução para alguém reconhecido 40 anos antes apenas como "um professor de cravo e solfa em algumas casas desta Corte".

\section{CONSIDERAÇÕES FINAIS}

Como já pontuado aqui, a carreira de Francisco Peres de Sousa foi, de certo ponto de vista, incomum. Até mesmo quando já tinha mais de 20 anos a lidar com grandes contratos régios, o dublê de músico e homem de negócios era acoimado de inepto para a prática mercantil. Ao longo do tempo, desconfianças em relação à origem e à profissão do cravista perpassam as falas de 
Costa Lavre, dos confrades do Espírito Santo, de Domingos Lopes Loureiro e de Tomé Gomes Moreira e seus descendentes.

Apesar disso, como vimos, Peres de Sousa soube capitalizar sua atividade de origem. Logrou, desse modo, estabelecer alianças com diversos homens de negócios e contar com a proteção, direta ou indireta, de poderosas autoridades, a ponto de ter-se tornado, ele mesmo, um grande contratador. Para recorrer aos termos de Bourdieu, valeu-se de seu capital cultural (o conhecimento de música) e do seu círculo de relações, construído seja enquanto professor particular seja de outras formas, inclusive do acesso privilegiado a poderosas autoridades, para construir um sólido capital econômico. Ou seja - para lembrar mais uma vez os termos propostos por Gil e Bertrand -, no mercado relacional em que se inseriam tais personagens, criou laços por meio de sua atividade de ensino, que se tornaram depois relações profícuas para seus empreendimentos comerciais.

Independentemente de suas habilidades, seja do ponto de vista interpessoal, seja como administrador, a despeito ou por causa mesmo de eventuais trapaças de que tenha lançado mão, o seu caso ilustra mecanismos do funcionamento do seleto círculo em que, no período pombalino, decidiam-se grandes negócios e políticas comerciais. $\mathrm{O}$ fato de um indivíduo com percurso estranho ao modelo normalmente obedecido pelos grandes comerciantes de sua época, mas próximo ao centro de poder, ter obtido sucesso em acumular cabedais e participar da administração de importantes negócios endossa, nesse caso concreto, o papel das relações pessoais no acesso ao rendoso mercado de contratos régios. Ainda que não seja possível generalizar a importância da proteção régia (ou de ministros, caso se pense em Pombal) nas contratações, os episódios aqui relatados, tanto os referentes diretamente a Peres de Sousa, quanto aqueles que envolveram os Quintelas, mostram que, pelo menos nos casos de algumas avenças mais vultosas, esse fator não pode ser descartado, embora somente a análise de outros casos particulares possa confirmar outras ocorrências semelhantes.

Obviamente, os aspectos aqui abordados não dão conta de toda a riqueza da trajetória de Peres de Sousa, cuja compreensão precisa considerar outros elementos, como as redes que estabeleceu no Brasil, tanto para angariar fundos, quanto para operacionalizar seus contratos. A investigação dessas relações pode colaborar para uma melhor compreensão a respeito de como se financiavam determinadas operações e de como funcionava o mercado relacional transatlântico em torno dos contratos régios, realidade em que os interesses de homens de negócios sediados nas duas margens do oceano se cruzavam. 
Esse é um terreno para o qual tem muito a contribuir, por exemplo, a abordagem das relações entre Peres de Sousa e figuras como João Hopman, Manuel Luís Vieira e os Coutos Pereiras, todos homens de negócios de peso no cenário fluminense.

\section{FONTES IMPRESSAS}

CONTRATO que se fez no Conselho Ultramarino, em observância do Real Decreto de Sua Majestade, de dezasete de Junho proximo passado, com Ignacio Pedro Quintella, e Companhia [...]. Lisboa: Officina de Antonio Rodrigues Galhardo, 1768.

CONTRATO que se fez no Conselho Ultramarino, em observância do Real Decreto de Sua Majestade, de dezesseis do corrente mês e ano, com Joaquim Pedro Quintela, Jacinto Fernandes Bandeira, Francisco Peres de Sousa e João Batista da Silva, do estanco do sal do Brasil [...] Lisboa: Oficina Patriarcal de Francisco Luiz Ameno, 1782 .

CONTRATOS da Pesca das Baleas do Rio de Janeiro, Ilhas de S. Catharina, e S. Sebastião, Santos, e S. Paulo [...] Lisboa: Officina de Miguel Manescal da Costa, 1755.

RATTON, Jacome. Recordaçoens de Jacome Ratton sobre as occurrencias do seu tempo em Portugal, de Maio 1747 a Setembro 1810. Londres: H. Bryer, 1843.

SILVA, Antonio Delgado da. Supplemento á Collecção de Legislação Portugueza [...]. Anno de 1763 a 1790. Lisboa: Typ. de Luiz Correa da Cunha, 1844, p. 76-79.

SILVA, Antonio Delgado da (comp.). Collecção de Legislação Portugueza desde a ultima compilação das Ordenações [...] Legislação de 1763 a 1774, 1829, p. 543-550.

\section{REFERÊNCIAS}

BARTH, Fredrik. Process and form in social life: v. I - selected essays of Fredrik Barth. London: Routledge \& Kegan Paul, 1981.

BERTRAND, Michel. Del actor a la red: análisis de redes e interdisciplinaridade. Nuevo Mundo Mundos Nuevos, Coloquios, [s. n.], p. 1-14, 2009. Disponível em: http:// nuevomundo.revues.org/index57505.html. Acesso em: 15 mar. 2019.

BOURDIEU, Pierre. Le capital social. Actes de la recherche en sciences sociales, v. 31, p. 2-3, janv. 1980. Disponível em: http://www.persee.fr/web/revues/home/prescript/ article/arss_0335-5322_1980_num_31_1_2069. Acesso em: 10 ago. 2018.

BRITO, Manuel Carlos de. Opera in Portugal in the Eighteenth Century. Cambridge: Cambridge University Press, 1989.

BURT, Ronald S. Brokerage and Closure: An Introduction to Social Capital. Oxford: Oxford University Press, 2007. 
CARDOZO, Manoel da Silveira. O desembargador João Fernandes de Oliveira. Coimbra: Ed. Universidade de Coimbra, 1979.

CARREIRA, António. As companhias pombalinas. Lisboa: Presença, 1983.

COLEMAN, James S. Foundations of Social Theory. [1990]. Cambridge, MA: Harvard University Press, 1994.

CROSSLEY, Nick et al. Social Network Analysis for Ego-Nets. Thousand Oaks, CA: SAGE, 2015.

ELLIS, Myriam. A baleia no Brasil Colonial: feitorias, baleeiros, técnicas, monopólio, comércio, iluminação. São Paulo: Melhoramentos: Edusp, 1969.

FALCON, Francisco José C. A época pombalina (política econômica e monarquia ilustrada). 2. ed. São Paulo: Ática, 1993.

GIL, Tiago. Redes e camadas de relacionamentos na economia: metodologias para o estudo da confiança mercantil na América Portuguesa do Antigo Regime. Revista de Indias, Madrid, v. LXXV, n. 264, p. 421-456, 2015.

GONÇALVES, Duarte. A Sociedade estabelecida para a subsistência dos Teatros Públicos da Corte - uma "companhia pombalina". População e Sociedade, Porto: Cepese, v. 22, p. 195-206, 2014.

KADUSHIN, Charles. Understanding Social Networks: Theories, Concepts, and Findings. Oxford: Oxford University Press, 2012.

MARCOS, Rui Manuel de F. As Companhias Pombalinas: contributo para a história das sociedades por acções em Portugal. Coimbra: Almedina, 1997.

MARTINS, Ana Rita P. M. D. A fábrica do Teatro do Bairro Alto (1761-1775). 2017. Tese (Doutorado em Estudos do Teatro) - Faculdade de Letras, Universidade de Lisboa. Lisboa, 2017.

MAXWELL, Kenneth. Marquês de Pombal: paradoxo do Iluminismo. Tradução: Antônio de Pádua Danesi. Rio de Janeiro: Paz e Terra, 1996.

MONTEIRO, Nuno Gonçalo. D. José. Lisboa: Temas e Debates, 2008.

PAZ, Marcelo de Oliveira. Companhia da Pescaria das Baleias nas Costas do Brasil (1765-1801): a caça ao Leviatã dos mares. 2015. Dissertação (Mestrado em Estudos Brasileiros) - Instituto de Ciências Sociais, Faculdade de Letras, Universidade de Lisboa. Lisboa, 2015.

PEDREIRA, Jorge Miguel. Os negociantes de Lisboa na segunda metade do século XVIII: padrões de recrutamento e percursos sociais. Análise Social, Lisboa, v. XXVII, p. 407-440, 1992.

PESAVENTO, Fábio. Um pouco antes da corte: a economia do Rio de Janeiro na segunda metade do Setecentos. Jundiaí, SP: Paco, 2013.

PESAVENTO, Fábio; GUIMARÃES, Carlos Gabriel. Contratos e contratadores no Atlântico Sul. História, histórias, Brasília, v. 1, n. 1, 2013. 
PINTO, Virgílio Noya. O ouro brasileiro e o comércio anglo-português: uma contribuição aos estudos da economia atlântica no século XVIII. 2. ed. São Paulo: Cia. Ed. Nacional, 1979.

PRELL, Christina. Social Network Analysis: History, Theory and Methodology. Los Angeles: SAGE, 2012.

SALVINO, Romulo Valle. Entre pontes e muros: tentativas de implantação do correio marítimo entre Portugal e o Brasil na primeira metade do século XVIII. Varia Historia, Belo Horizonte: UFMG, v. 34, n. 64, p. 15-49, jan./abr. 2018a.

SALVINO, Romulo Valle. Guerras de papel: disputas e estratégias em torno da comunicação escrita na América portuguesa (c. 1650 - c. 1750). 2018. Tese (Doutorado em História) - Universidade de Brasília (UnB). Brasília, 2018.

SAMPAIO, Antonio Carlos Jucá de. A economia do Império português no período pombalino. In: FALCON, Francisco; RODRIGUES, Claudia (org.). A "Época Pombalina" no mundo luso-brasileiro. Rio de Janeiro: Ed. FGV, 2015.

SILVA, Janice Theodoro da. Alexandre de Gusmão: um diplomata na Corte. São Paulo: Secretaria de Estado da Educação: Imprensa Oficial, 2006.

\section{NOTAS}

${ }^{1}$ A respeito da teoria e das metodologias aplicáveis à análise de redes sociais, verificar, entre outros: BURT, 2007; KADUSHIN, 2012; PRELL, 2012; CROSSLEY et al., 2015.

${ }^{2}$ No que se refere aos percursos sociais dos homens de negócios, ver: PEDREIRA, 1992.

${ }^{3}$ A respeito das diferentes visões sobre capital social, além de Bourdieu e Coleman, consultar: BURT, 2007, passim; CROSSLEY et al., 2015, p. 25-38.

${ }^{4}$ AHU, Bahia, cx. 108, doc. 42. ant. 22 set. 1745. Requerimento do enfermeiro-mor e tesoureiro do hospital real ao rei [D. João V] solicitando conceder ao assistente do correio no Estado do Brasil Francisco Peres de Sousa o privilégio de ter prontos alguns paquebotes [...]. Todas as referências, neste trabalho, ao caso dos navios-correio, quando não especificadas, remetem a este documento.

${ }^{5}$ PRICES, wages and rents in Portugal - 1300-1910. Disponível em: $<$ http://pwr-portugal. ics.ul.pt/>. Acesso em: 2 abr. 2019.

${ }^{6} \mathrm{AHU}$, Bahia, cx. 108, doc. 42. ant. 22 set. 1745. Sobre as tentativas anteriores de implantação de navios-correio: SALVINO, 2018a.

${ }^{7}$ AHU, Mato Grosso, cx. 4, doc. 249.

${ }^{8}$ A respeito do declínio de Gusmão, ver: SILVA, 2006, p. 14. Sobre a fim da Confraria do Espírito Santo: FALCON, 1993, p. 375-376; MAXWELL, 1996, p. 69-70. No que tange aos principais aspectos administrativos e econômicos do período pombalino, podem ser consultados, entre outros: FALCON, 1993; MAXWELL, 1996; MONTEIRO, 2008; SAMPAIO, 
2015. Especificamente sobre as companhias de comércio, verificar: CARREIRA, 1983; MARCOS, 1997.

${ }^{9}$ AHU_ACL_CU_17, cx. 103, D. 8762. “Consulta do Conselho Ultramarino à rainha [D. Maria I] sobre o requerimento de Tomé de Castro Correia de Sá [...] em que solicitava boa arrematação do contrato das baleias do Rio de Janeiro, Santos e São Paulo [...]”.

${ }^{10}$ Temos notícia dessas ocorrências em: AHU, Rio de Janeiro, cx. 53, doc. 64; AHU_ACL_ CU_17, cx. 103, D. 8762; AHU - Rio de Janeiro, cx. 137, doc. 24.

${ }^{11}$ AHU_ACL_CU_17, cx. 103, D. 8762.

${ }^{12}$ CONTRATOS, 1755. Ver também: AHU_ACL_CU_17, cx. 103, D. 8762; AHU, Rio de Janeiro, cx. 56, doc. 40; cx. 57, doc. 27. Segundo um documento da década de 1780, Peres de Sousa teria sido sócio "na quarta parte" do contrato com Pedro Gomes Moreira: AHU, Rio de Janeiro, cx. 129, docs. 43, 35. "Requerimento de Tomé de Castro Corrêa de Sá [...] à rainha $[\ldots] "$ ".

${ }^{13}$ AHU, São Paulo, caixa 25, doc. 2419. Caetano do Couto Pereira faleceu antes de 1756, como se pode ver em: AHU, Rio de Janeiro, cx. 83, docs. 19161-19166.

${ }^{14}$ AHU_ACL_CU_17, cx. 103, D. 8762; AHU, Rio de Janeiro, cx. 67, doc. 47.

${ }^{15}$ AHU, Bahia, cx. 35, doc. 6735.

${ }^{16}$ No que se refere às ocorrências relatadas neste parágrafo, consultar: AHU, São Paulo, caixa 25, doc. 2419; AHU, Rio de Janeiro, cx. 110, doc. 67. Ver também: Carta de Joaquim Pedro Quintela, de 16 abr. 1786, apud PAZ, 2015, p. 163.

${ }^{17}$ Não confundir João Fernandes de Oliveira, o velho, com seu filho homônimo, também contratador dos diamantes, pois, em 1776, o sócio em questão já estava morto, conforme se pode verificar em: AHU, Rio de Janeiro, cx. 110, doc. 67. João Fernandes de Oliveira, o filho, somente morreria em 1779. A respeito da data das mortes de ambos, ver: CARDOZO, 1979, p. 309-310.

${ }^{18}$ AHU_ACL_CU_17, cx. 103, D. 8762; AHU, Rio de Janeiro, cx. 110, doc. 67. Ver também: ELLIS, 1969, p. 153-154; PAZ, 2015, p. 66; 79. Os “outros Peres" mencionados por Ratton eram José Pereira de Sousa Peres (além de sobrinho, afilhado) e Joaquim Pereira de Sousa Peres, que apareceriam depois na documentação como herdeiros de Francisco.

${ }^{19}$ AHU, São Paulo, caixa 25, doc. 2419; AHU, Baía, cx. 160, doc. 21; AHU, Bahia, cx. 161, doc. 27. Sobre o fim das frotas, ver, entre outros: PINTO, 1979.

${ }^{20}$ AHU, Rio de Janeiro, cx. 105, docs. 40, 41; Bahia, cx. 173, doc. 23. Ver também: SILVA, 1829 , p. 760-761.

${ }^{21}$ AHU, Contratos do Sal, Códice 306. "Contrato que se fes no Conselho Ultramarino em observancia ao Real Decreto de Sua Majestade de dois do corrente mes e anno, com Ignacio Pedro Quintella e Seos Socios do Estanco do Brazil [...]”.

${ }^{22}$ SILVA, 1829, p. 542-550. Ver também: BRITO, 1989, p. 92-93; 182-183; 217; GONÇALVES, 2014, p. 195-206; MARTINS, 2017, p. 127. 
${ }^{23}$ AHU, Rio de Janeiro, cx. 144, doc. 62; AHU, RJ-avulsos, cx. 104, doc. 8797; AHU, RJ-avulsos, cx. 104, doc. 881.

${ }^{24}$ AHU, Rio de Janeiro, cx. 111, doc. 12; AHU, RJ-avulsos, cx. 102, doc. 8749.

${ }^{25}$ AHU, Contratos do Sal, cx. 1, doc. 75 e 76; CONTRATO, 1782.

${ }^{26}$ AHU, Rio de Janeiro, cx. 129, docs. 43, 45.

${ }^{27}$ AHU, Rio de Janeiro, cx. 129, doc. 77; cx. 130, doc. 28.

${ }^{28}$ ANTT, Feitos Findos, Inventários post mortem, Letra F, mç. 92, n. 17, "Inventário de bens de Francisco Peres de Sousa".

${ }^{29}$ AHU, Rio de Janeiro, cx. 129, docs. 43, 45. 